\title{
Thrombin-Induced Microglial Activation Produces Degeneration of Nigral Dopaminergic Neurons In Vivo
}

\author{
Sang-H. Choi, ${ }^{1,2}$ Eun H. Joe ${ }^{1,2,3}$ Seung U. Kim, ${ }^{1,2}$ and Byung K. Jin ${ }^{1,2}$ \\ ${ }^{1}$ Brain Disease Research Center, ${ }^{2}$ Neuroscience Graduate Program, and ${ }^{3}$ Department of Pharmacology, Ajou University School of Medicine, \\ Suwon 442-749, Korea
}

The present study examined whether thrombin-induced microglial activation could contribute to death of dopaminergic neurons in the rat substantia nigra (SN) in vivo. Seven days after thrombin injection into the SN, tyrosine hydroxylase immunohistochemistry showed a significant loss of nigral dopaminergic neurons. In parallel, thrombin-activated microglia, visualized by immunohistochemical staining using antibodies against the complement receptor type 3 (OX-42) and the major histocompatibility complex class II antigens were also observed in the SN, where degeneration of nigral neurons was found. Reverse transcription PCR at various time points demonstrated that activated microglia in vivo exhibited an early and transient expression of inducible nitric oxide synthase (iNOS), cyclooxygenase-2 (COX-2), and several proinflammatory cytokines, including interleukin $1 \beta$ (IL-1 $\beta$ ), IL-6, and tumor necrosis factor $\alpha$. Western blot analysis and double-label immunohistochemistry showed an increase in the expression of iNOS and COX-2 and the colocalization of these proteins within microglia. The thrombin-induced loss of SN dopaminergic neurons was partially inhibited by $N^{\mathrm{G}}$-nitro-L-arginine methyl ester hydrochloride, an NOS inhibitor, and by DuP-697, a COX-2 inhibitor. Additional studies demonstrated that extracellular signalregulated kinase 1/2 (ERK1/2) and p38 mitogen-activated protein kinase (MAPK) were activated in the SN as early as 30 min after thrombin injection, and that these kinases were localized within microglia. Inhibition of ERK1/2 and p38 MAPK reduced iNOS and COX-2 mRNA expression and rescued dopaminergic neurons in the SN. The present results strongly suggest that microglial activation triggered by endogenous compound(s) such as thrombin may be involved in the neuropathological processes of dopaminergic neuronal cell death that occur in Parkinson's disease.

Key words: thrombin; microglia; inducible nitric oxide synthase; cyclooxygenase-2; mitogen-activated protein kinase; proinflammatory cytokines; dopaminergic neurons; Parkinson's disease

\section{Introduction}

Parkinson's disease (PD) is a common neurodegenerative disorder associated with a dramatic loss of dopaminergic neurons in the substantia nigra (SN; Giasson and Lee, 2001). Although little is known about the cause of $\mathrm{PD}$, a growing body of evidence supports the notion that activated microglia play a critical role in the degeneration of nigral dopaminergic neurons (Hirsch, 2000; Le et al., 2001; Vila et al., 2001). Many studies have reported the presence of reactive microglia in the SN of PD patients (Hunot et al., 1999; Knott et al., 2000) and in the SN of animal models of PD produced by administration of 1-methyl-4-phenyl-1,2,3,6tetrahydropyridine (MPTP; Kohutnicka et al., 1998; Liberatore et al., 1999; Dehmer et al., 2000; Wu et al., 2002) or 6-hydroxydopamine (6-OHDA; He et al., 2001; Rodrigues et al., 2001; Cicchetti et al., 2002). In vivo and in vitro studies have shown that death of dopaminergic neurons can also be produced

Received July 30, 2002; revised May 12, 2003; accepted May 12, 2003.

This work was supported by Korea Science and Engineering Foundation (KOSEF) Grant R11-1998-052-08000-0 through the Brain Disease Research (enter at Ajou University (B.K.J.), KOSEF Frontier 21 Project Grant 1999-2-210002-5, and Neurobiology Research Program Grant M1-0108-00-0028 from the Korea Ministry of Science and Technology (B.K.J.).

Correspondence should be addressed to Byung K. Jin, Brain Disease Research Center, Ajou University School of Medicine, Suwon 442-749, Korea. E-mail: bkjin@madang.ajou.ac.kr.

Copyright $\odot 2003$ Society for Neuroscience $\quad$ 2270-6474/03/235877-10\$15.00/0 by microglial activators such as lipopolysaccharide (LPS; Castano et al., 1998; Kim et al., 2000). Additionally, $\beta$-amyloid (A $\beta$ ) and prion have been implicated in the processes of neurodegeneration through the activation of microglia (Meda et al., 1995; Combs et al., 1999; Brown, 2001). In this regard, it has been suggested that microglia activator(s) could be involved in the pathogenesis of neurodegenerative diseases, including PD. This hypothesis is supported by our most recent finding that trisilaoganglioside (GT1b), a component of the neuronal membrane, triggers in vivo degeneration of nigral dopaminergic neurons via microglial activation (Ryu et al., 2002a).

Thrombin is generated from the precursor prothrombin endogenously expressed in human, mouse, and rat brain, including dopaminergic neurons in the SN (Dihanich et al., 1991; Soifer et al., 1994; Weinstein et al., 1995). Prothrombin also exists and circulates in blood at micromolar levels (Fenton, 1986). Cerebrovascular injury triggers the rapid conversion of prothrombin to thrombin, resulting in extravasation into the CNS (Gingrich and Traynelis, 2000). In rat brain treated with thrombin, infiltration of inflammatory cells, brain edema, and reactive gliosis were observed (Nishino et al., 1993). In addition, thrombin induces various biological responses in the CNS, although its effect on neurons and astrocytes is either protective or toxic, depending on the thrombin concentration. Increased thrombin in brain has been 
shown to lead to the degeneration of the hippocampal neurons (Striggow et al., 2000), spinal motoneurons (Turgeon et al., 1998), and astrocytes (Donovan et al., 1997). Recently, we (Lee at al., 2001) and Debeir et al. (1998) reported that thrombin was directly toxic to dopaminergic neurons in mesencephalic cultures containing few of microglia. However, these results do not rule out the involvement of microglia in thrombin-induced neurotoxicity in vivo. In this regard, recent studies, including ours, clearly demonstrate that thrombin activates cultured microglia, leading to increased production of proinflammatory cytokines, inducible nitric oxide synthase (iNOS), and nitric oxide (NO; Möller et al., 2000; Ryu et al., 2000; Suo et al., 2002), which have been proposed to play a pathological role in several neurodegenerative disorders such as PD and Alzheimer's disease (Dickson et al., 1993; Boka et al., 1994; Hunot et al., 1999; Hirsch, 2000).

All of these observations raise the possibility that thrombin may contribute to neurodegenerative diseases both directly, through toxicity to neurons, and indirectly, through activation of microglia. In the present study, we examined whether thrombin could activate microglia in vivo by injecting this protease into the rat $\mathrm{SN}$ and whether activated microglia were implicated in thrombin-induced degeneration of dopaminergic neurons in the $\mathrm{SN}$. We also investigated the molecular mechanisms underlying microglial activation by thrombin. Our results suggest that thrombin can activate microglia in vivo via mitogen-activated protein kinases (MAPKs) such as extracellular signal-regulated kinase 1/2 (ERK1/2) and p38 MAPK, and this microglial activation can mediate degeneration of dopaminergic neurons in the $\mathrm{SN}$ by increased expression of iNOS, cyclooxygenase-2 (COX-2), and proinflammatory cytokines from activated microglia.

\section{Materials and Methods}

Chemicals. Chemicals were purchased from the following companies: thrombin, Sigma (St. Louis, MO); $N^{\mathrm{G}}$-nitro-L-arginine methyl ester hydrochloride (L-NAME), Tocris (Ellisville, MO); DuP-697, Cayman Chemical (Ann Arbor, MI), and PD98059 and SB203580, Calbiochem (La Jolla, CA). The vehicle used to dissolve both thrombin and L-NAME was sterile PBS. PD98059 and SB203580 were dissolved in 1\% dimethylsulfoxide in PBS. DuP-697 was dissolved in dimethylformamide (DMF) and then diluted with PBS (1:1 solution of DMF/PBS).

Stereotaxic injection of thrombin. All experiments were done in accordance with approved animal protocols and guidelines established by Ajou University. Female Sprague Dawley rats (260-280 gm) were anesthetized with injection of chloral hydrate $(360 \mathrm{mg} / \mathrm{kg}$, i.p.) and positioned in a stereotaxic apparatus (Kopf Instrument, Tujunga, CA), and they received a unilateral administration of thrombin into the right $\mathrm{SN}$ [anteroposterior (AP), -5.3 ; mediolateral $(\mathrm{ML}),-2.3$; and dorsoventral (DV), $-7.6 \mathrm{~mm}$ from bregma] according to the atlas of Paxinos and Watson (1998). Thrombin was injected at a rate of $0.2 \mu \mathrm{l} / \mathrm{min}$ using a 26 gauge Hamilton (Reno, NV) syringe attached to an automated microinjector (Buwon, Seoul, Korea). After injection, the needle was left in place for an additional $5 \mathrm{~min}$ before slow retraction. Intact (nontreated) or PBS-treated animals were used as controls. Animals were killed by an overdose of chloral hydrate for further studies.

Pretreatment with L-NAME, DuP-697, PD98059, and SB203580. L-NAME $(50 \mathrm{mg} / \mathrm{kg})$, an NOS inhibitor, or DuP-697 (5 mg/kg), a specific COX-2 inhibitor, were administered intraperitoneally $1 \mathrm{hr}$ before thrombin injection. PD98059 (100 $\mu \mathrm{M})$, an MAPK kinase (MEK) inhibitor, and SB203580 $(50 \mu \mathrm{M})$, a p38 MAPK inhibitor, were administered into the right ventricle ( $\mathrm{AP},-0.6$; $\mathrm{ML},-1.6$; and $\mathrm{DV},-4.0 \mathrm{~mm}$ from bregma) 30 min before intranigral thrombin injection under general anesthesia described above. Animals were killed for further studies. Doses of these inhibitors were chosen in accordance with those of previous studies (Iadecolar et al., 1994; Alessi et al., 1995; Li et al., 1997; Sugino et al., 2000).

Tissue preparation and immunohistochemistry. Animals were transcardially perfused with a saline solution containing $0.5 \%$ sodium nitrate and heparin $(10 \mathrm{U} / \mathrm{ml})$ and then fixed with $4 \%$ paraformaldehyde dissolved in $0.1 \mathrm{M}$ phosphate buffer $(\mathrm{PB})$. Brains were removed from the skull, postfixed overnight in buffered $4 \%$ paraformaldehyde at $4^{\circ} \mathrm{C}$, stored in a $30 \%$ sucrose solution for $24-48 \mathrm{hr}$ at $4^{\circ} \mathrm{C}$ until they sank, were frozen sectioned on a sliding microtome in $40-\mu \mathrm{m}$-thick coronal sections. All sections were collected in six separate series and processed for immunohistochemical staining as described previously (Ryu et al., 2002a). In brief, brain sections were rinsed in PBS and then incubated overnight at room temperature with primary antibodies. The following day, brain sections were rinsed with PBS and $0.5 \%$ bovine serum albumin (BSA), incubated with the appropriate biotinylated secondary antibody, and processed with an avidin-biotin complex kit (Vectastain ABC kit; Vector Laboratories, Burlingame, CA). The bound antiserum was visualized by incubating with $0.05 \%$ diaminobenzidine- $\mathrm{HCl}$ (DAB) and $0.003 \%$ hydrogen peroxide in $0.1 \mathrm{M} \mathrm{PB}$. The $\mathrm{DAB}$ reaction was stopped by rinsing tissues in 0.1 M PB. Labeled tissue sections were then mounted on gelatin-coated slides and analyzed under a bright-field microscope (Nikon, Mellville, NY). The primary antibodies were used anti-OX-42 [specific for complement receptor type 3 (CR3), 1:200; Serotec, Oxford, UK], anti-OX-6 (specific for major histocompatibility complex class II antigens, 1:200; PharMingen, San Diego, CA, USA), and ED1 (specific for glycosylated lysosomal antigen, 1:200; Serotec) for microglia, anti-neuron-specific nuclear protein (NeuN, 1:200; Chemicon) for neurons, anti-tyrosine hydroxylase (TH, 1:2000; Pel-Freez Biologicals, Rogers, AR) for dopaminergic neurons, anti-glutamic acid decarboxylase (GAD, 1:1000; Sigma) for GABAergic neurons, and GFAP (1:500; Sigma) for glial fibrillary acidic protein in astrocytes.

For Nissl staining, some of the SN tissues were mounted on gelatincoated slides, dried for $1 \mathrm{hr}$ at room temperature, stained in $0.5 \%$ cresyl violet, dehydrated, coverslipped, and then analyzed under a bright-field microscope (Nikon).

Stereological cell counts. The unbiased stereological estimation of the total number of the TH-immunopositive (TH-ip) cells in the SN was made using the optical fractionator, as previously described in detail with some modifications (Kirik et al., 1998, 2000). This sampling technique is not affected by tissue volume changes and does not require reference volume determinations (West et al., 1991). The borders of the SN at all levels in the rostocaudal axis were defined. As previously described (Kirik et al., 1998), the medial border was defined by a vertical line passing through the medial tip of the cerebral peduncle, by the medial terminal nucleus of the accessory nucleus of the optic tract for excluding the TH-ip cells in the ventral tegmental area (VTA), or both. The ventral border followed the dorsal border of the cerebral peduncle, thereby including the TH-ip cells in the pars reticulata, and the area extended laterally to include the pars lateralis in addition to the pars compacta. The sections used for counting covered the entire SN from the rostral tip of the pars compacta back to the caudal end of the pars reticulata (AP, -4.5 to -6.3 $\mathrm{mm}$ from bregma, according to the atlas of Paxinos and Watson, 1998). This generally yielded eight or nine sections in a series. Sampling was done using the Computer-Assisted Stereological Toolbox system, version 2.1.4 (Olympus Denmark A/S, Ballerup, Denmark), using an Olympus BX51 microscope, a motorized microscope stage (Prior Scientific, Rockland, MA) run by an IBM-compatible computer, and a microcator (Heidenhain ND 281B) connected to the stage and feeding the computer with the distance information in the $z$-axis. The $\mathrm{SN}$ was delineated at a $1.25 \times$ objective and generated counting areas of $150 \times 150 \mu \mathrm{m}$. A counting frame $\left(1612 \mu \mathrm{m}^{2}\right)$ was placed randomly on the first counting area and systemically moved through all counting areas until the entire delineated area was sampled. The sampling frequency was chosen so that $\sim 130 \mathrm{TH}$-ip cells were counted in each specimen on the contralateral side. Actual counting was performed using a $100 \times$ oil objective. Guard volumes ( $4 \mu \mathrm{m}$ from the top and $4-6 \mu \mathrm{m}$ from the bottom of the section) were excluded from both surfaces to avoid the problem of lost caps, and only the profiles that came into focus within the counting volume (with a depth of $10 \mu \mathrm{m}$ ) were counted. The estimate of the total number of neurons was calculated according to the optical fractionator formula (West et al., 1991).

Immunofluorescence double labeling. For double-immunofluorescence staining, tissue sections were processed as described previously (Ryu et al., 2002a). Briefly, free-floating sections were mounted on gelatin- 
coated slides and dried for $1 \mathrm{hr}$ at room temperature. After washing in PBS, sections were incubated in $0.2 \%$ Triton X-100 for $30 \mathrm{~min}$ and rinsed three times with $0.5 \%$ BSA. The sections were incubated in a combination of a rabbit polyclonal antibody to iNOS (Upstate Biotechnology, Lake Placid, NY; diluted at 1:100), COX-2 (Cayman Chemical; 1:200), phospho-ERK1/2 (Cell Signaling; 1:100), or phospho-p38 MAPK (Cell Signaling; $1: 100)$ and either a mouse monoclonal antibody against OX-42 (Serotec; $1: 100$ ) or a mouse monoclonal antibody against GFAP (Sigma; 1:100) overnight at $4^{\circ} \mathrm{C}$. After washing in PBS, the sections were incubated simultaneously with a mixture of FITC-conjugated goat antimouse IgG (Vector Laboratories; 1:100) and Texas Red-conjugated goat anti-rabbit IgG (Vector Laboratories; 1:100) for $1 \mathrm{hr}$ at room temperature. Slides were coverslipped with Vectashield medium (Vector Laboratories) and viewed using an IX71 confocal laser scanning microscope (Olympus Optical, Tokyo, Japan). To analyze the localization of different antigens in double-stained samples, images were obtained from the same area and merged using interactive software.

Reverse transcription PCR analysis. After thrombin injections, rats were killed at 1,4,8,12, 24, and $94 \mathrm{hr}$ (four or five at each time interval from each group), and the $\mathrm{SN}$ area was rapidly removed from the brains and frozen at $-70^{\circ} \mathrm{C}$. Total RNA was extracted from dissected tissue using RNAzol B (Tel-Test, Friendwood, TX) according to the manufacturer's instructions and quantified spectrophotometrically. Reverse transcription (RT) was performed using Superscript II reverse transcriptase (Invitrogen, Rockville, MD) according to the manufacturer's instructions. The primers for interleukin $1 \beta$ (IL-1 $\beta$ ), IL-6, tumor necrosis factor $\alpha$ (TNF- $\alpha$ ), iNOS, and COX-2 were as follows: $5^{\prime}$-TGA TGT TCC CAT TAG ACA GC-3' (sense) and 5'-GAG GTG CTG ATG TAC CAG TT-3' (antisense) for IL-1 $\beta, 5^{\prime}$-AAA ATC TGC TCT GGT CTT CTG G-3' (sense) and $5^{\prime}$-GGT TTG CCG AGT AGA CCT CA-3' (antisense) for IL-6, 5' -GTA GCC CAC GTC GTA GCA AA-3' (sense) and 5' -CCC TTC TCC AGC TGG GAG AC- $3^{\prime}$ (antisense) for TNF- $\alpha, 5^{\prime}$-GCA GAA TGT GAC CAT CAT GG-3' (sense) and 5' -ACA ACC TTG GTG TTG AAG GC-3' (antisense) for iNOS (557 bp), and 5' -CCA TGT CAA AAC CCG TGG TGA ATG-3' (sense) and 5'-ATG GGA GTT GGG CAG TCA TCA G-3' (antisense) for COX-2 (374 bp). The PCR cycles consisted of denaturation at $94^{\circ} \mathrm{C}$ for $30 \mathrm{sec}$, annealing at $55^{\circ} \mathrm{C}$ for $30 \mathrm{sec}$ (IL- $1 \beta$, TNF- $\alpha$, iNOS, and COX-2) or $60^{\circ} \mathrm{C}$ for $30 \mathrm{sec}$ (IL-6), and extension at $72^{\circ} \mathrm{C}$ for 90 sec for 30 cycles. Glyceraldehyde-3-phosphate dehydrogenase was also amplified as an internal PCR control using the following primers: $5^{\prime}$ TCC CTC AAG ATT GTC AGC AA-3' (sense) and 5'-AGA TCC ACA ACG GAT ACA TT-3' (antisense). The temperature cycling conditions were as follows: $2 \mathrm{~min}$ at $94^{\circ} \mathrm{C}, 25 \mathrm{cycles}$ of $94^{\circ} \mathrm{C}$ for $30 \mathrm{sec}, 55^{\circ} \mathrm{C}$ for $30 \mathrm{sec}$, and $72^{\circ} \mathrm{C}$ for $90 \mathrm{sec}$, and a final extension at $72^{\circ} \mathrm{C}$ for $10 \mathrm{~min}$. The PCR product was separated by electrophoresis on a $1.5 \%$ agarose gel, stained with ethidium bromide, and then detected under UV light.

Western immunoblot analysis. As described previously (Ryu et al., 2002a), animals receiving intranigral injection of thrombin or PBS as a control were killed at the indicated time points, and the $\mathrm{SN}$ area was rapidly removed from the brains and frozen at $-70^{\circ} \mathrm{C}$. For gel electrophoresis and Western blotting, the $\mathrm{SN}$ was homogenized with $0.5 \mathrm{ml}$ of ice-cold lysis buffer containing 20 mM Tris-HCl, pH 7.5, 1 mM EDTA, 5 $\mathrm{mm} \mathrm{MgCl}_{2}, 1 \mathrm{~mm}$ dithiothreitol (DTT), $20 \mu \mathrm{g} / \mathrm{ml}$ aprotinin, and $1 \mathrm{~mm}$ phenylmethylsulfonyl fluoride (PMSF). Aliquots of total tissue homogenate were frozen and kept at $-70^{\circ} \mathrm{C}$. The protein concentration was determined using a BCA kit. Equal amounts of protein $(50 \mu \mathrm{g})$ were loaded in each lane with loading buffer containing $62.5 \mathrm{~mm}$ Tris- $\mathrm{HCl}, \mathrm{pH}$ 6.8, $2 \%$ SDS, $10 \%$ glycerol, $50 \mathrm{~mm}$ DTT, and $0.1 \%$ (w/v) bromphenol blue. Samples were boiled at $100^{\circ} \mathrm{C}$ for $2 \mathrm{~min}$ before gel loading. Homogenate samples were electrophoresed on 10-12\% SDS-polyacrylamide gel and transferred to polyvinylidene difluoride membranes (Millipore, Bedford, MA) using an electrophoretic transfer system (Bio-Rad, Hercules, CA). The membranes were then blocked in TNE buffer (in mM: 10 Tris-HCl, pH 7.5, $50 \mathrm{NaCl}$, and 2.5 EDTA, pH 8.0) containing 5\% skim milk for $1 \mathrm{hr}$ with gentle shaking. Membranes were then incubated overnight at $4^{\circ} \mathrm{C}$ with the primary anti-rabbit polyclonal antibodies in TNE containing 5\% skim milk, respectively. The following primary antibodies and dilutions were used: iNOS (1:500), COX-2 (1:500), ERK1/2 (1:1000), and p38 MAPK (1:1000). After washing, the membranes were incubated with horseradish peroxidase-conjugated anti-rabbit IgG secondary antibody (Amersham Biosciences, Piscataway, NJ) diluted 1:2000 for $1 \mathrm{hr}$ at room temperature and washed again. The blots were developed with an enhanced chemiluminescence kit according to the manufacturer's instructions (Amersham Biosciences). For gel electrophoresis and Western blotting of active forms of p38 MAPK and ERK1/2, the SN was homogenized with $0.5 \mathrm{ml}$ of ice-cold lysis buffer containing $20 \mathrm{~mm}$ Tris- $\mathrm{HCl}, \mathrm{pH}$ 7.5, $1 \mathrm{~mm}$ EDTA, $5 \mathrm{~mm} \mathrm{MgCl}$, $1 \mathrm{~mm}$ DTT, $20 \mu \mathrm{g} / \mathrm{ml}$ aprotinin, $1 \mathrm{~mm}$ PMSF, and $2 \mathrm{~mm}$ sodium orthovanadate. After SDS-PAGE and electrophoretic transfer, membranes were blocked with $1 \%$ BSA for $1 \mathrm{hr}$ at room temperature, incubated overnight at $4^{\circ} \mathrm{C}$ with the primary anti-rabbit polyclonal phosphorylated forms of p38 MAPK and ERK1/2 diluted 1:1000 in TNE buffer with 1\% BSA, and processed as described above.

Measurement of the densities of the immunoblot bands. For semiquantitative analysis of immunoblot bands, the density of each band was measured with a computer imaging device and accompanying software (Bio-Rad). The background value was subtracted from all other readings.

Statistical analysis. All values are expressed as mean \pm SEM. Statistical significance ( $p<0.05$ for all analyses) was assessed by ANOVA using Instat 3.05 (GraphPad, San Diego, CA), followed by Student-NewmanKeuls analyses.

\section{Results}

Thrombin induces degeneration of dopaminergic neurons in the $\mathrm{SN}$ in vivo

Thrombin or PBS as a control was unilaterally microinjected into the SN of rats. Seven days later, brains were removed, and sections were processed for Nissl staining and immunostaining for $\mathrm{NeuN}$ to detect general nigral neurons or for $\mathrm{TH}$ to specifically detect dopaminergic neurons in the SN. In the SN treated with thrombin, a dramatic reduction in Nissl-stained cells was induced (Fig. 1C,D) compared with PBS-treated SN (Fig. 1A,B). Moreover, PBS-treated SN had a clear defined nucleus and prominent Nissl substances when compared with thrombin-treated $\mathrm{SN}$, showing marked loss of Nissl substances with gliosis. NeuN and $\mathrm{TH}$ immunohistochemical staining was performed on sections adjacent to those used for Nissl staining. Thrombin-treated SN displayed a significant loss of NeuN-ip (Fig. 1G,H) and TH-ip (Fig. $1 K, L$ ) cells in the SN when compared with PBS-treated SN, respectively (Fig. $1 E, F, I, J$ ). In highly magnified photographs, thrombin-induced degenerating neurons appeared as shrunken and rounded cell bodies with few processes (Fig. $1 L$ ), in contrast to healthy and large dopaminergic neurons with long and branched neuritic processes in PBS-treated controls (Fig. 1J). All of these observations indicated that $\mathrm{TH}$-ip cells in the $\mathrm{SN}$ were substantially destroyed. Additional immunostaining also showed a significant loss of GAD-ip neurons (GABAergic neurons) in the substantia nigra reticulata $(\mathrm{SNr})$ after intranigral injection of thrombin (Fig. 1O,P) compared with PBS-treated SN (Fig. $1 M, N)$.

\section{Thrombin induces microglial activation and produces proinflammatory cytokines in the $\mathrm{SN}$ in vivo}

Recent findings, including ours, indicated that thrombin activated cultured rat microglia (Möller et al., 2000; Ryu et al., 2000; Suo et al., 2002). The present study determined the activation of microglia in the SN by thrombin in vivo. Sections adjacent to those used for TH immunostaining in Figure 1 were processed for immunohistochemical staining using antibodies against OX-42, OX-6, and ED1 to detect microglial activation as described previously (Ryu et al., 2002a). In PBS-treated SN, the majority of OX-42-ip microglia exhibited resting morphology, specifically small cell bodies and thin, long, or ramified processes (Fig. 2A). Consistent with our previous report (Ryu et al., 2002a), activated microglia with larger cell bodies with short, thick, or no processes 
in PBS-treated SN were observed only along the needle tract because of mechanical damage. In marked contrast, however, thrombin triggered profound activation of microglia in the SN, with enhanced staining intensity and activated morphology in OX-42-ip cells (Fig. 2B). The data also showed that thrombin treatment resulted in many OX-6-ip cells in the SN (Fig. 2D), whereas in PBS-treated controls, OX-6-ip cells were seen exclusively along the needle tract (Fig. 2C). Microglia appeared to reach a state similar to that of active phagocytes (Fig. 2F), as determined by ED1 immunohistochemical staining, which labels phagocytic microglia, in particular, the presence of accumulating intracellular lipid vacuoles (Popovich et al., 1997). ED1-ip cells were undetectable in the $\mathrm{SN}$ on either the contralateral side (data not shown) or the PBS-treated side as controls (Fig. 2E). Additional examination clearly showed thrombin-induced morphological changes of OX-42-ip microglia, from resting to activated, as early as $4 \mathrm{hr}$ after injection (Fig. $2 \mathrm{H}$ ), compared with nontreated (Fig. $2 G$ ) or PBS-treated (Fig. 2A) SN. It appeared that $24 \mathrm{hr}$ after thrombin injection resulted in more activated microglia than seen $4 \mathrm{hr}$ after thrombin injection (Fig. 2I). Accompanying these results, there was no substantial loss of nigral dopaminergic neurons as determined by Western blot analysis of $\mathrm{TH}$ in the SN at 1, 4, 12, and $24 \mathrm{hr}$ after intranigral injection of thrombin (data not shown), indicating that microglial activation occurred before the lesion of nigral dopaminergic neurons.

Given the effects of thrombin-induced neurotoxicity and microglial activation, we next sought to determine whether intranigral injection of thrombin produced microglia-derived proinflammatory cytokines such as IL- $1 \beta$, IL- 6 , and TNF- $\alpha$. RT-

PCR analysis showed the induction of IL- $1 \beta$, IL- 6 , and TNF- $\alpha$ mRNA expression as early as $1 \mathrm{hr}$ after thrombin injection (Fig. 3 ). Although expression of IL- $1 \beta$ and TNF- $\alpha$ mRNA was maintained up to $96 \mathrm{hr}$ after injection, IL-6 mRNA expression returned to normal levels at $96 \mathrm{hr}$ after thrombin treatment.

\section{Thrombin-induced iNOS and COX-2 expression is localized within activated microglia in the $\mathrm{SN}$ in vivo}

We examined whether intranigral injection of thrombin induced expression of iNOS and COX-2 in the SN. RT-PCR analysis demonstrated in vivo that thrombin induced iNOS and COX-2 expression as early as 4 and $1 \mathrm{hr}$ after injection, respectively (Fig. 3). In parallel, the results of Western blot analysis showed that thrombin upregulated iNOS expression, with maximal levels reached $12 \mathrm{hr}$ after injection and levels returning to basal $48 \mathrm{hr}$ after injection (Fig. $4 A, B$ ). In contrast to thrombin-treated $\mathrm{SN}$, iNOS expression was inconsiderable
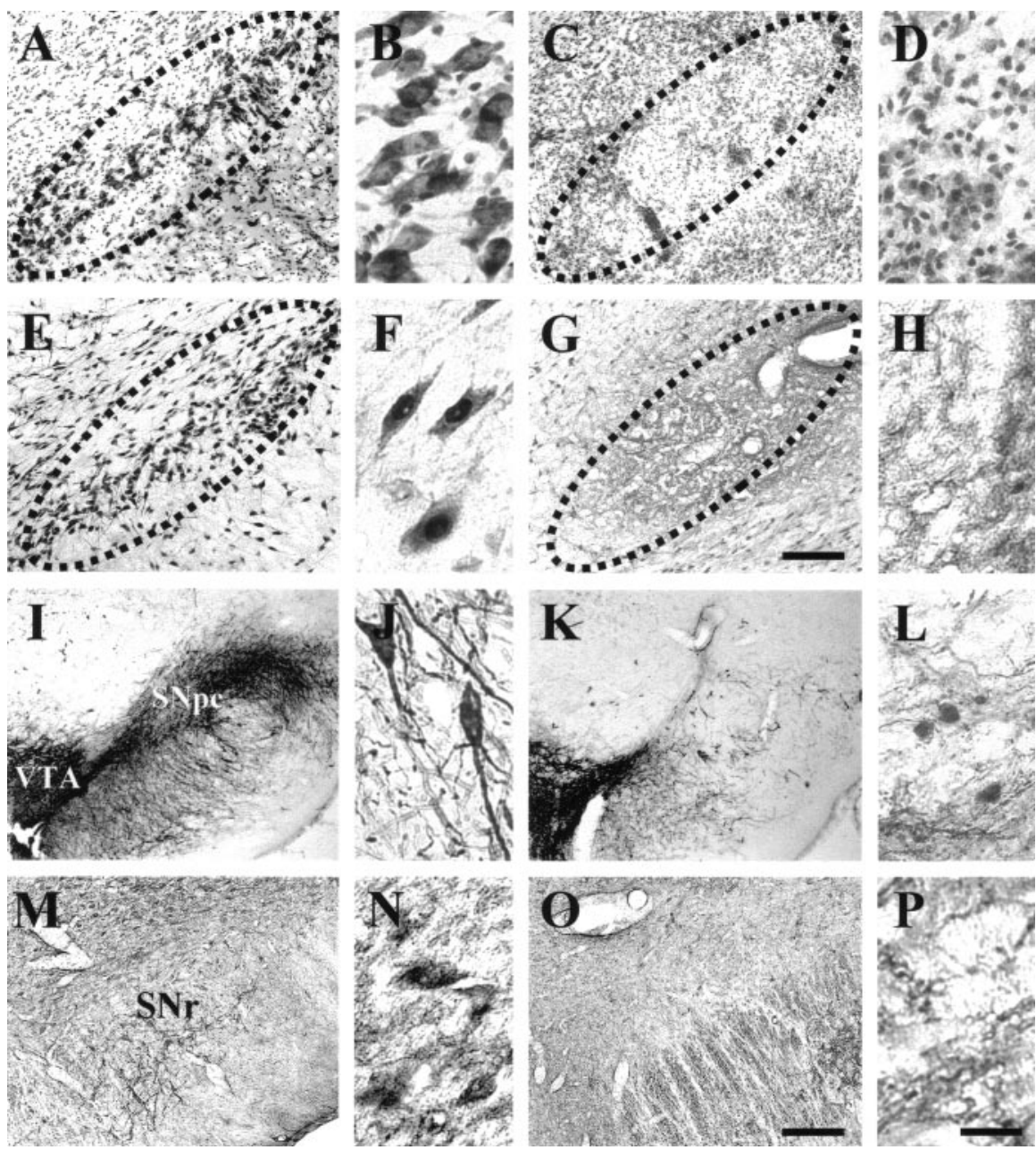

Figure 1. Thrombin-induced in vivo neurotoxicity on dopaminergic neurons in the SN. PBS $(A, B, E, F, I, J, M, N)$ or thrombin $(C$, $D, G, H, K, L, O, P ; 20 \mathrm{U} / 4 \mu$ l) was unilaterally injected into the $S N$. Animals were killed $7 \mathrm{~d}$ after injection; brains were removed; and sections $(40 \mu \mathrm{m})$ were cut using a sliding microtome. Every sixth serial section was selected and processed for Niss $E-H$, NeuN immunohistochemical staining in the $S N$. Note a significant reduction of NeuN-ip cells in thrombin-treated $S N(G, H)$ staining in the SN.J, L, Higher magnifications of $I, K$, respectively.M-P, GAD immunohistochemical staining in the SNr. N, $P$, Higher magnifications of $M, O$, respectively. These data were are representative of six to eight animals per group. Dotted lines indicate substantia nigra pars compacta (SNpc) where dopaminergic neurons were degenerated. Scale bars: $A, C, E, G, M, 0,200 \mu \mathrm{m} ; I, K$, $250 \mu \mathrm{m} ; B, D, F, H, J, L, N, P, 50 \mu \mathrm{m}$.

in PBS-treated (12 hr) or nontreated ( $0 \mathrm{hr}) \mathrm{SN}$ as controls. In the thrombin-treated $\mathrm{SN}$, expression of COX-2 protein was observed as early as $1 \mathrm{hr}$ after injection and maintained up to $24 \mathrm{hr}$ after injection (Fig. $4 E$ ). To further evaluate the cellular location of iNOS and COX-2 expression, doubleimmunofluorescence staining with a combination of antibodies of iNOS and OX-42, iNOS and GFAP, or COX-2 and OX-42 was performed. Activated microglia stained with OX-42 antibody were visible $12 \mathrm{hr}$ after thrombin injection (Fig. 4C,F, green). Increased immunofluorescence of iNOS or COX-2 was also seen in the SN $12 \mathrm{hr}$ after thrombin injection (Fig. 4C,F, red), consistent with the data obtained from Western blot analysis. Simultaneous imaging of immunofluorescence on the same tissue sections revealed that thrombininduced iNOS and COX-2 expression was localized in activated microglia. In agreement with our previous findings (Ryu et al., 2002a), thrombin-induced iNOS expression was not found in astrocytes (Fig. $4 D$ ). 


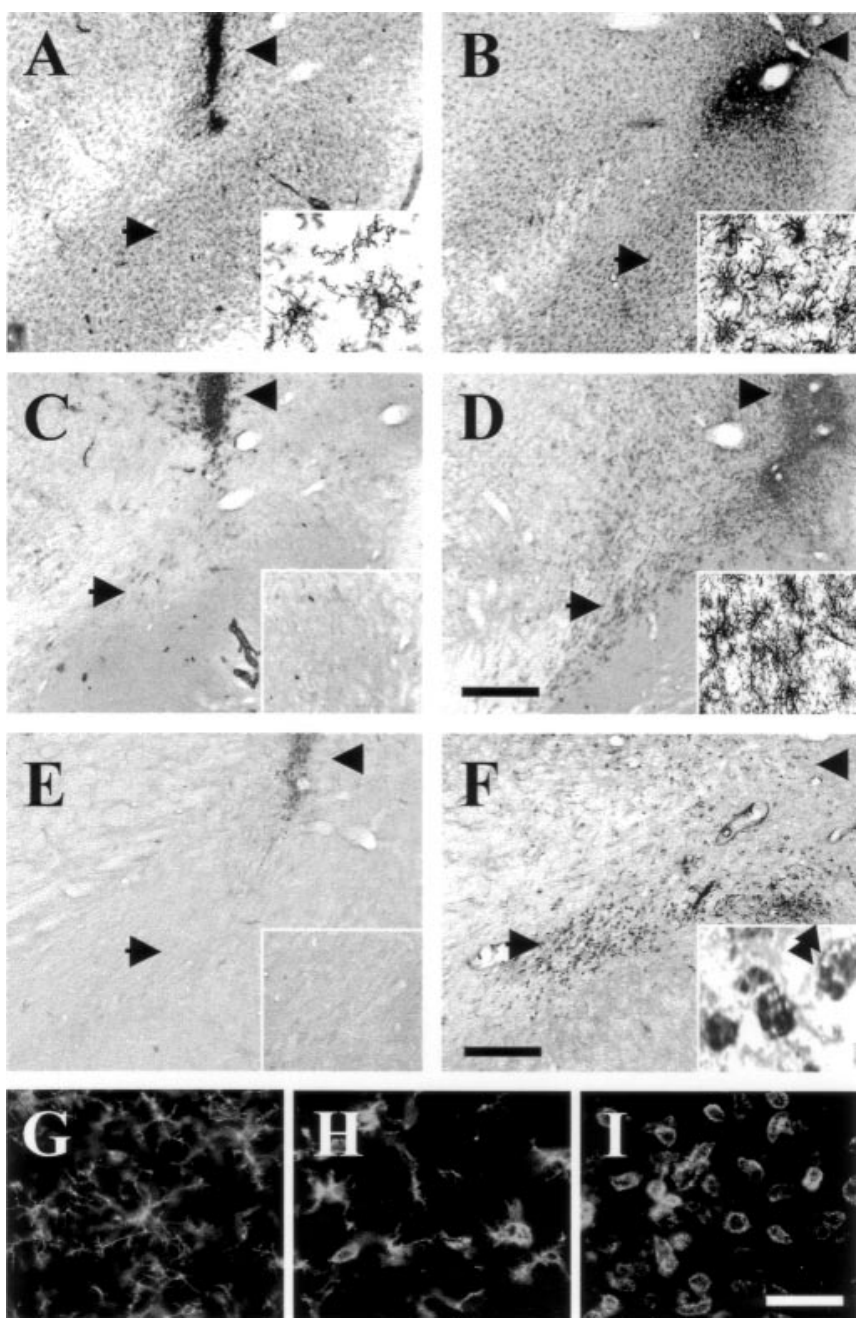

Figure 2. Thrombin-induced microglial activation in the $S N . A-F$, Sections $(A, C, E, P B S ; B, D$, $F$, thrombin) adjacent to those used in Figure 1 were immunostained with $0 X-42$ (CR3; $A, B$ ), OX-6 (major histocompatibility complex class II; C, D), or ED1 (glycosylated lysosomal antigen; $E_{,}$ $F)$ antibodies for microglia. The data are representative of six to eight animals used for each experimental group. Insets, Highly magnified areas of OX-42, OX-6, and ED1 immunoreactivity indicated by arrows. Arrowheads indicate needle tracts. Accumulating intracellular lipid vacuoles are denoted by arrowheads in F, inset. $G-I$, Morphological changes of microglia from the resting state $(G$; small cell bodies and thin, long, or ramified processes) to the activated state $(H$, I; larger cell bodies with short, thick, or no processes) in the $\mathrm{SN}$ after thrombin injection. Animals receiving unilateral injection of thrombin $(20 \mathrm{U})$ in the $\mathrm{SN}$ were killed at 4 or $24 \mathrm{hr}$ after injection; brains were removed; and coronal sections ( $40 \mu \mathrm{m}$ ) were cut using a sliding microtome. Every sixth serial section was selected, immunostained with $0 X-42$ antibody as a marker of microglia, and visualized by FITC-conjugated secondary antibody. The $0 X-42$-ip microglia were observed in the contralateral SN (G) as controls and in the ipsilateral SN at $4 \mathrm{hr}(H)$ and $24 \mathrm{hr}(I)$ after thrombin injection. These data are representative of five to seven animals per group. Scale bars: $A-D, 250 \mu \mathrm{m} ; E, F, 200 \mu \mathrm{m} ; G-I, 50 \mu \mathrm{m}$

\section{Neurotoxic actions of iNOS and COX-2 on degeneration of dopaminergic neurons in the $\mathrm{SN}$ in vivo}

We hypothesize that NO, released by activated microglia as a result of thrombin-stimulated iNOS expression, contributed to the degeneration of nigral dopaminergic neurons. To test this, we investigated whether L-NAME, an NOS inhibitor, altered the effects of thrombin on nigral dopaminergic neurons in the $\mathrm{SN}$. Intraperitoneal treatment with L-NAME partially rescued TH-ip neurons (Fig. 5C). When quantified and expressed as a percentage of neurons on the ipsilateral compared with the contralateral side (I/C \%), L-NAME was found to increase the number of TH-ip neurons by 22\% ( $p<0.01$; Fig. $5 D)$. As controls, vehicle

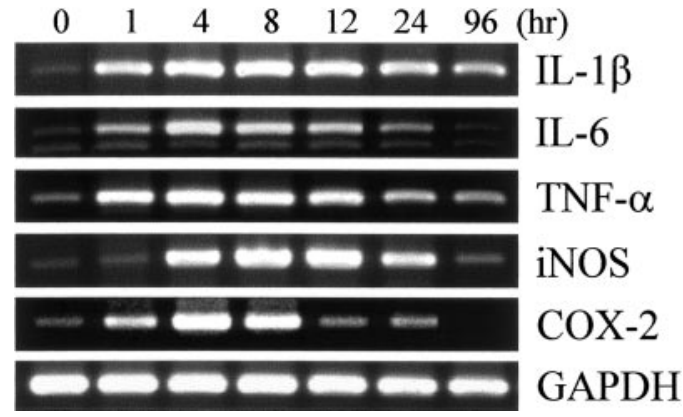

Figure 3. RT-PCR analysis of thrombin-induced mRNA expression of proinflammatory cytokines, iNOS, and COX-2 in the SN. Total RNA was isolated in the ipsilateral SN at indicated time points after intranigral thrombin injection $(20 \mathrm{U})$. These results are representative of four or five independent replicate experiments.

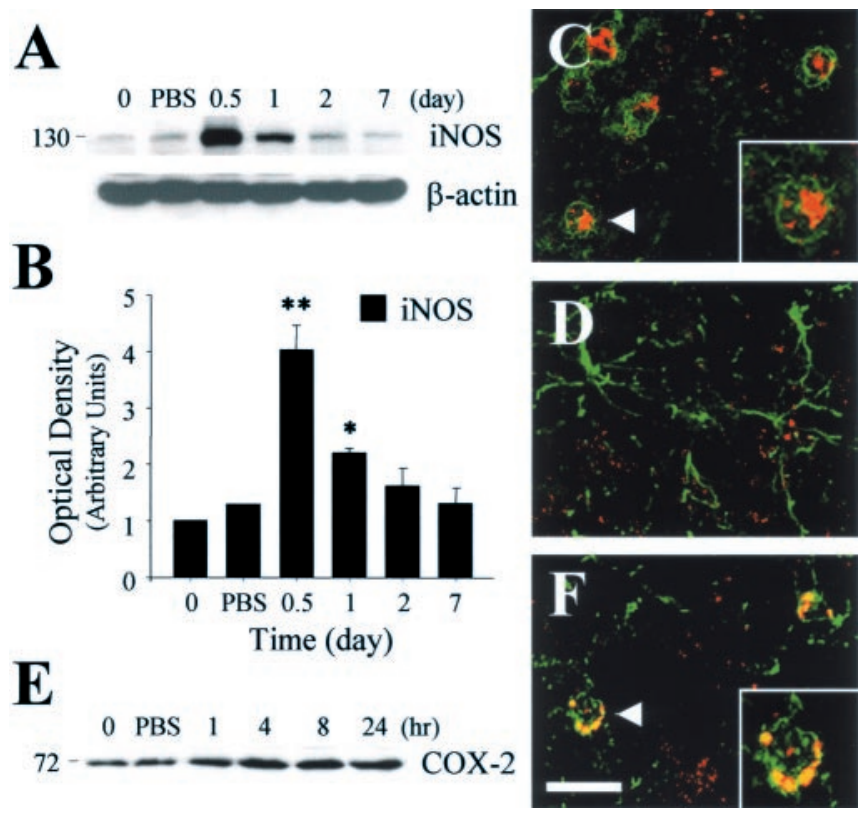

Figure 4. Thrombin-induced iNOS and COX-2 protein expression in activated microglia. $A$, Western blot analysis showing levels of iNOS expression in the SN at indicated time points after intranigral thrombin injection (20 U). Nontreated or PBS-treated (12 hr) SN was used as a control. $B$, Mean \pm SEM of four or five pooled samples per time point. ${ }^{*} p<0.05$; ${ }^{* *} p<0.01$, significantly different from control ( 0 or $12 \mathrm{hr}$ after PBS treatment; ANOVA and Student-Newman-Keuls analyses). C, D, Colocalization of iNOS immunoreactivity within the activated microglia. The sections of rat SN were immunostained simultaneously with iNOS and $0 X-42$ as a marker of microglia ( $C$ ) or iNOS and GFAP as a marker of astrocytes $(D)$ and then visualized by FITC- and Texas Red-conjugated secondary antibodies $12 \mathrm{hr}$ after thrombin injection (20 U), respectively. Each image was captured from the same area and merged. Note that iNOS $(C$, red) was detected in numerous activated microglia $(C$, green) but not in astrocytes $(D$, green). $E$, Western blot analysis showing levels of $\mathrm{COX}$-2 expression in the $\mathrm{SN}$ at indicated time points after intranigral thrombin injection ( $20 \mathrm{U}$ ). Nontreated or PBS-treated (4 hr) SN was used as a control. $F$, Colocalization of COX-2 immunoreactivity within activated microglia. Inset, Highly magnified cell marked by an arrowhead. Scale bar, $50 \mu \mathrm{m}$.

(PBS) or L-NAME alone had no effects (data not shown) (Ryu et al., 2002a).

To determine whether COX-2 expression contributed to thrombin-induced dopaminergic neurodegeneration, we also used the relatively selective COX-2 inhibitor DuP-697 (Li et al., 1997). In SN treated with DuP-697, the loss of TH-ip neurons was partially attenuated. When quantified and expressed as I/C $\%$, DuP-697 was found to increase the number of TH-ip neurons by $17 \%(p<0.01$; Fig. $5 D)$. As controls, vehicle or Dup-697 alone had no effects (data not shown). 


\section{Thrombin activates ERK1/2 and p38 MAPK localized within microglia in the $\mathrm{SN}$ in vivo}

Recently, we reported that thrombin activated cultured rat microglia via MAPKs, such as ERK1/2 and p38 MAPK (Ryu et al., 2000). Thus, we examined the involvement of MAPKs in the SN in vivo in the process of microglial activation after intranigral injection of thrombin. The activation of these two MAPKs was determined by Western blot analysis, using specific antibodies for the phosphorylated forms of ERK1/2 (P-ERK1/2) and p38 MAPK (P-p38 MAPK). The results of Western blot assays showed that thrombin upregulated the levels of both P-ERK1/2 and P-p38 MAPK in the ipsilateral SN as early as $30 \mathrm{~min}$ after thrombin treatment (Fig. 6A,B). In contrast, these MAPKs were slightly visible in nontreated $(0 \mathrm{hr})$ or PBS-treated (30 min after PBS) $\mathrm{SN}$ as controls.

To clarify the cellular location of activated MAPKs, double-immunofluorescence staining was performed with a combination of antibodies against P-ERK1/2 and OX-42 or P-p38 MAPK and OX-42. Activated microglia stained with OX-42 antibody were visible $8 \mathrm{hr}$ after thrombin injection (Fig. $6 C, F$ ). Increased P-ERK1/2 (Fig. 6D) and P-p38 MAPK (Fig. 6G) immunofluorescence was also seen in the SN $8 \mathrm{hr}$ after thrombin injection, consistent with the results of Western blot analyses. Simultaneous imaging of immunofluorescence on the same tissue sections revealed that thrombin-activated ERK1/2 and p38 MAPK were colocalized within microglia (Fig. 6E,H).

Inhibitors of MAPK pathways rescue dopaminergic neurons in the $\mathrm{SN}$ from thrombin-induced neurotoxicity in vivo To elucidate the physiological functions of MAPK activation in microglia after thrombin injection, we examined whether thrombin-induced expression of iNOS, COX-2, and proinflammatory cytokines and degeneration of dopaminergic neurons in the SN could be affected by MAPKs inhibitors. For this purpose, PD98059 (100 $\mu \mathrm{M})$, a specific MEK inhibitor, and SB203580 (50 $\mu \mathrm{M})$, a p38 MAPK inhibitor, were administered intraventricularly $30 \mathrm{~min}$ before intranigral injection of thrombin $(20 \mathrm{U})$. Animals were killed $4 \mathrm{hr}$ (Fig. 7A) or $7 \mathrm{~d}$ (Fig. 7B,C) after thrombin treatment, and brain tissues were prepared for RT-PCR analysis or sectioned for immunostaining with TH antibody for dopaminergic neurons or OX-42 antibody for microglia in the SN. The results of RT-PCR assays showed that these MAPK inhibitors dramatically attenuated the thrombin-induced expression of iNOS and COX-2 mRNA, whereas PD98058 or SB203580 alone had little effect on the iNOS and COX-2 expression as controls (Fig. 7A). This inhibitory effect appeared more prominent when these inhibitors were administered simultaneously. Intriguingly, however, these inhibitors did not alter expression of other proinflammatory cytokines, including IL- $1 \beta$, IL- 6 , and TNF- $\alpha$, tested in this study. Accompanying the downregulation of molecular events, these MAPK inhibitors morphologically inhibited microglial activation, as determined by OX-6 immunohistochemical

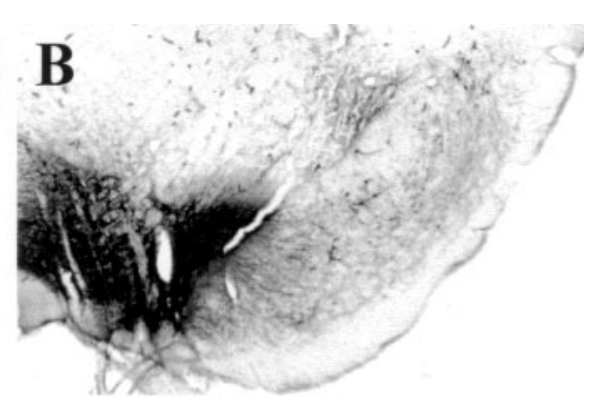

D

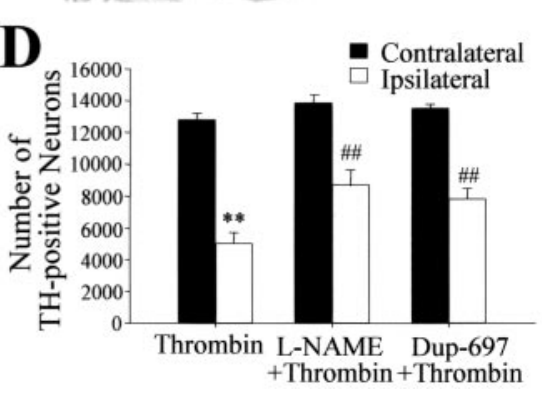

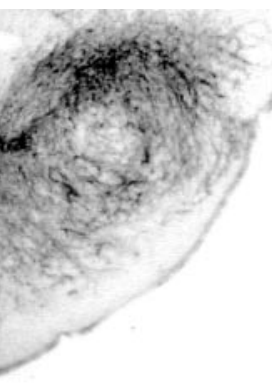

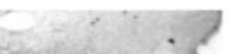

Figure 5. L-NAME or DuP-697 protects thrombin-induced neuronal death. $A-C$, TH immu L-NAME on the thrombin-induced degeneration of dopaminergic neurons in the SN. TH-ip neurons in the contralateral $\mathrm{mg} / \mathrm{kg}$, i.p.) was administered $1 \mathrm{hr}$ before intranigral injection of thrombin (20 U). Scale bar, $250 \mu \mathrm{m}$. D, Number of TH-ip neurons 列 eight animals were used for each experimental group. The results represent mean \pm SEM. ${ }^{* *} p<0.01$, significantly different from contralateral side; ${ }^{\# \#} p<0.01$, significantly different from ipsilateral side treated with thrombin only (ANOVA and Student-Newman-Keuls analyses).

staining (Fig. 7C). Because both iNOS and COX-2 were implicated in thrombin-induced degeneration of nigral dopaminergic neurons, and MAPK inhibitors reduced iNOS and COX-2 expression (Fig. 5), we speculated that these inhibitors could contribute to survival of dopaminergic neurons in the $\mathrm{SN}$. As a result, at $7 \mathrm{~d}$ after intranigral thrombin injection, TH immunohistochemistry revealed that intraventricular administration of these inhibitors protected dopaminergic neurons from thrombininduced neurotoxicity. When quantified and expressed as I/C \%, both PD98059 and SB203580 were found to increase the number of TH-ip neurons by 20\% $(p<0.05)$ and 31\% $(p<0.01)$, respectively, compared with ipsilateral $\mathrm{SN}$ treated with thrombin only (Fig. 7B). As controls, these inhibitors alone had no effects on neuronal survival (data not shown).

\section{Discussion}

Recently, we provided evidence for direct neurotoxic actions of thrombin against dopaminergic neurons in neuron-enriched and microglia-scarce mesencephalic cultures (Lee et al., 2001). However, the possibility remained that the thrombin-induced neurotoxicity observed in vivo was attributable, at least in part, to microglial activation stimulated by this serine protease in the SN. This is because thrombin can activate cultured microglia, resulting in the production of proinflammatory factors, cytotoxic factors, or both that in turn can affect the onset of neurodegeneration, the progression of neurodegeneration, or both (Möller et al., 2000; Ryu et al., 2000; Suo et al., 2002).

The present study is the first to demonstrate that thrombininduced neurotoxicity of dopaminergic neurons in the $\mathrm{SN}$ in vivo is mediated by significant activation of microglia, with expression of iNOS, COX-2, and proinflammatory cytokines. The localiza- 

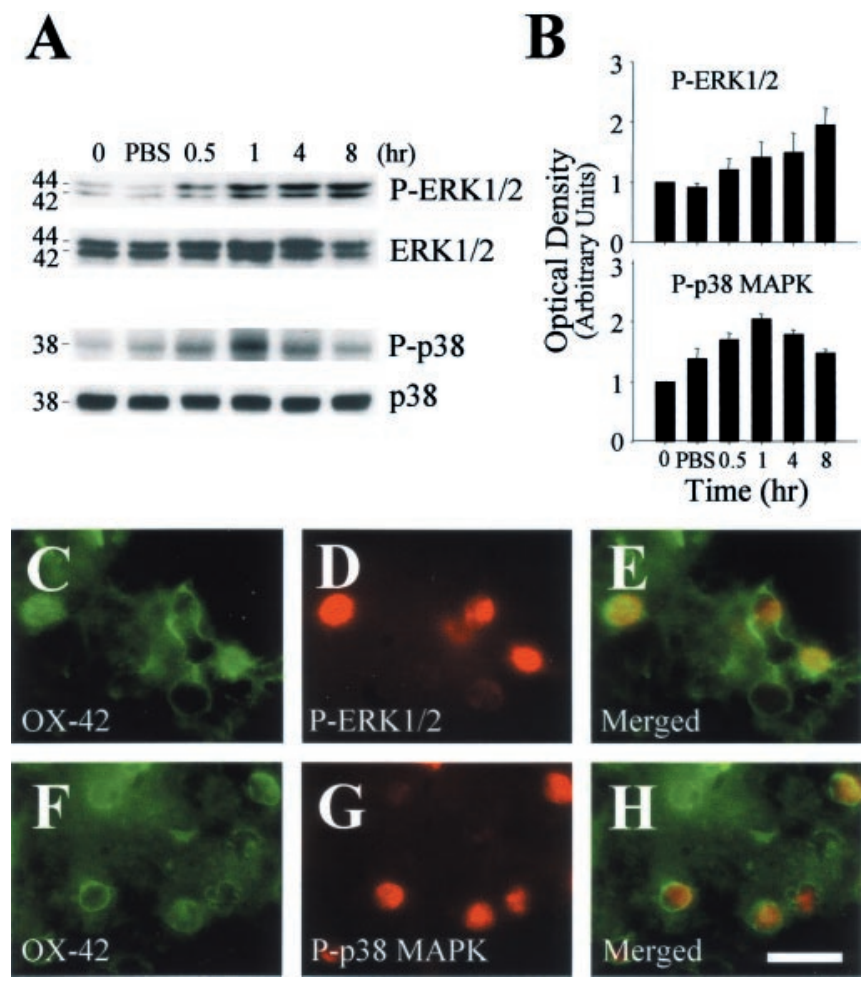

Figure 6. Activation of MAPKs by thrombin in the SN. A, Expression of ERK1/2 and p38 MAPK protein in the SN. Tissue homogenates were prepared from ipsilateral SN treated with thrombin $(20 \mathrm{U})$ for the indicated times and subjected to Western blot analysis using specific antibodies that recognize P-ERK1/2 and P-p38 MAPK. The blots were then reprobed with antibody against total ERK1/2 and p38 MAPK. The results are representative of four independent replicate experiments. $B$, Mean \pm SEM of four pooled samples at indicated time points. $C-H$, Colocalization of P-ERK1/2 or P-p38 MAPK immunoreactivity within activated microglia in the SN $8 \mathrm{hr}$ after intranigral injection of thrombin (20 U). P-ERK1/2 (D) and P-p38 MAPK ( $G$ ) were detected by Texas Red immunofluorescence (red) with an antibody against the phosphorylated forms of these kinases. OX-42 $(C, F)$ as a marker of microglia was visualized with the FITC-conjugated secondary antibody (green). Each image was captured from the same area and merged $(E, H)$. Scale bar, $25 \mu \mathrm{m}$.

tion of iNOS and COX-2 in activated microglia and the protection of dopaminergic neurons from thrombin-induced cell death by an NOS inhibitor (L-NAME) and a COX-2 inhibitor (DuP697) underscore the pathological significance of iNOS and COX-2 expression in microglia. Importantly, the thrombinstimulated activation of ERK1/2 and p38 MAPK, the localization of these two MAPKs within activated microglia, and the reduction in iNOS and COX-2 expression and resultant increase in the survival of dopaminergic neurons by inhibition of these MAPKs strongly suggest that the MAPK signaling pathway is the mechanism underlying thrombin-induced microglial activation in the $\mathrm{SN}$ in vivo.

Microglia are intrinsic immune effector cells in the CNS, and activation of microglia is a common phenomenon in response to neural tissue injury (Kreutzberg, 1996; Aloisi, 2001; Nakajima and Kohsaka, 2001). Microglial activation is generally determined by the gradual change of morphology from a quiescent ramified form (resting state) to an amoeboid form (activated state) within hours (Stence et al., 2001). This is consistent with our results in which the majority of microglia displayed activated morphology (larger cell bodies with short, thick, or no process) as early as $4 \mathrm{hr}$ after thrombin injection.

Accompanying this morphological transformation, activated microglia can produce several potentially neurotoxic substances, including $\mathrm{NO}$ and prostaglandins synthesized by iNOS and COX-2, respectively. Microglia-derived NO has been presumed to be neurotoxic (Chao et al., 1992; McMillian et al., 1997), although the presence of iNOS in human microglia is still controversial (Colasanti et al., 1995; Walker et al., 1995; Ding et al., 1997; Zhao et al., 1998). The current study provides strong evidence for a role of NO in thrombin-induced degeneration of nigral dopaminergic neurons. We found that thrombin upregulated iNOS mRNA and protein expression, whereas L-NAME partially prevented dopaminergic neuron death. These results are consistent with previous studies showing that in iNOS-deficient mice, nigral dopaminergic neurons were protected from MPTP toxicity (Liberatore et al., 1999; Dehmer et al., 2000) and that LPS-induced iNOS expression and NO production in microglia (Murphy et al., 1993) led to the death of dopaminergic neurons in the SN (Castano et al., 1998; Kim et al., 2000). Recently, we also demonstrated in vivo that NO mediated the degeneration of dopaminergic neurons in the SN treated with GT1b (Ryu et al., 2002a).

In vivo and in vitro studies demonstrated that the prostanoidsynthesizing enzyme COX-2 was markedly upregulated in microglia in rodent brain after LPS treatment (Bauer et al., 1997; Minghetti et al., 1999) and in human brain during chronic cerebral ischemia (Tomimoto et al., 2000). This is consistent with the present finding that thrombin-induced COX-2 expression in the $\mathrm{SN}$ is localized within microglia. These results suggest that microglia may represent an important source of prostanoids in the brain, although COX-2 expression has been also localized in neurons (Nogawa et al., 1997; Minghetti et al., 1999). A growing body of evidence indicates that increased levels of COX-2 and prostanoids are implicated in neurodegeneration in cortical, hippocampal, and spinal motor neurons (Drachman and Rothstein, 2000; Hewett et al., 2000; Araki et al., 2001; Kim et al., 2001; Kunz and Oliw, 2001; Mirjany et al., 2002). These studies have also shown that COX-2-mediated neurotoxicity is prevented by COX-2 inhibitors. The current study strongly supports the hypothesis that microglia-derived COX-2 participates in thrombininduced death of dopaminergic neurons in the SN. Here we provide clear evidence that thrombin produces COX-2 expression, localized in microglia, whereas DuP-697, a COX-2 inhibitor, partially attenuates the loss of dopaminergic neurons. These data are in agreement with recent studies showing that inhibition of COX-2 can protect dopaminergic neurons from cell death in the MPTP model of PD (Teismann and Ferger, 2001).

Although our results point to a likely role of iNOS and COX-2 in thrombin-mediated neurotoxicity in the SN, the possibility remains that other microglia-derived proinflammatory factors, cytotoxic factors, or both may also be involved. Candidate factors include NMDA receptor agonists (Giulian et al., 1993), TNF- $\alpha$ (Kim et al., 2000), IL-1 $\beta$, and quinolinic acid (Espey et al., 1997). The likelihood of the involvement of such factors is supported by our observations that other proinflammatory mediators, including IL- $1 \beta$, IL- 6 , and TNF- $\alpha$, are also expressed in the SN after thrombin treatment.

The MAPK (ERK1/2, p38, and c-Jun N-terminal kinase/ stress-activated protein kinase) signaling pathways were found to be common mediators of microglial activation (Bhat et al., 1998; Pyo et al., 1998, 1999; Ryu et al., 2000, 2002b; Tikka et al., 2001). The results of these studies showed ERK1/2- and p38 MAPKmediated microglial activation in cultured rat microglia after treatment with a variety of microglial activators, including LPS, $\mathrm{A} \beta$, gangliosides, thrombin, prothrombin kringle 2, and glutamate, resulting in increased production of $\mathrm{NO}$ and expression of 
iNOS, COX-2, or both. This effect was abolished by inhibitors of the ERK1/2 (PD98059) or p38 MAPK (SB203580) pathway. These in vitro data are consistent with our present findings that thrombin induced both ERK1/2 and p38 MAPK expression in microglia in the $\mathrm{SN}$ in vivo, and inhibitors of two MAPKs reduced expression of iNOS and COX-2 and consequently prevented death of nigral dopaminergic neurons. These results strongly suggest central roles for these kinase cascades in the thrombin-induced microglial activation that contributes to neurotoxicity. In contrast to iNOS and COX-2 mRNA expression, inhibitors of two MAPKs, added separately or simultaneously, did not attenuate thrombininduced expression of proinflammatory cytokines such as IL- $1 \beta$, IL- 6 , and TNF- $\alpha$, which are implicated in neurotoxicity. Although the exact mechanisms of this apparent differential regulation remain to be explored, these results suggest posttranscriptional regulation of the induction of these cytokines. Recent studies in other laboratories support this interpretation. In LPS-treated microglia in culture, MAPK inhibitors attenuated expression of iNOS mRNA and protein and TNF- $\alpha$ protein but not TNF- $\alpha$ mRNA (Bhat et al., 1998).

Activation of the ERK1/2 pathway is not restricted to microglia but also found in neurons in response to various stimuli, and its effect on neurons is either neuroprotective or neurotoxic. The capacity of the ERK1/2 signaling pathway to exert neuroprotective effects is well documented in global cerebral ischemia (Hu et al., 2000; Sugino et al., 2000) and on hypoxic cortical neurons (Jin et al., 2002). In contrast, however, several lines of evidence suggest that sustained activation of ERK1/2 can be deleterious after hyperexcitation and focal ischemic injury (Murray et al., 1998; Alessandrini et al., 1999; Wang et al., 2001) and in the CNS-derived TH-expressing cell line treated with 6-OHDA (Kulich and Chu, 2001). Regarding this, we examined and found that intraventricular treatment with PD98059 alone had little effects on the neuronal death in the SN (data not shown), whereas PD98059 prevented thrombininduced death of dopaminergic neurons by inhibiting microglial activation (Fig. 7). However, these results cannot rule out the alternative hypothesis that blockade of this signaling pathway in neurons reduces thrombin-induced death of dopaminergic neurons in the SN. This interpretation is supported the observation that P-ERK was localized within nigral dopaminergic neurons at $12 \mathrm{hr}$ after intranigral injection of thrombin (data not shown; our unpublished observation). All of these results collectively underscore the need to carefully use and to further thoroughly study ERK1/2 inhibitors.

In summary, the present results showed possible involvement of thrombin-activated microglia in the degeneration of nigral dopaminergic neurons. Thrombin may activate microglia through activation of MAPKs such as ERK1/2 and p38 MAPK by phosphorylation of these proteins. Activated microglia can induce iNOS and COX-2 expression, consequently leading to death
B
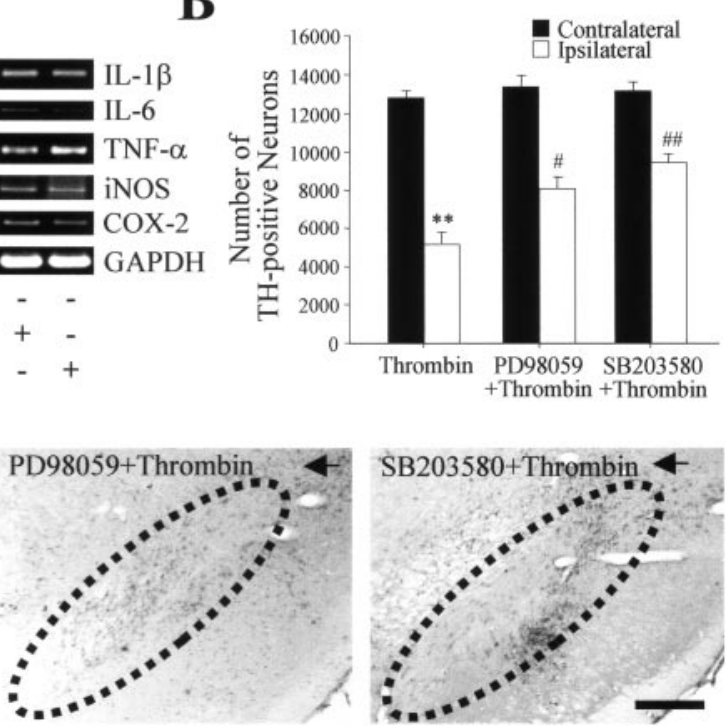

Figure 7. Effect of PD98059 and SB203580 on survival of dopaminergic neurons after thrombin injection into SN. An MEK

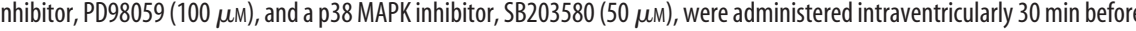
a thickness of $40 \mu \mathrm{m}$, and every sixth serial section was immunohistochemically stained with antibodies against TH for

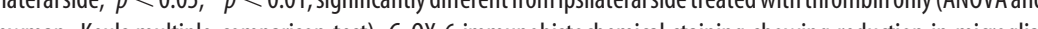
activation by MAPK inhibitors. Every sixth serial section adjacent to those used in $B$ was immunohistochemically stained with antibodies against $0 X-6$ for microglia. Dotted lines indicate substantia nigra pars compacta where dopaminergic neurons were degenerated after thrombin. Arrows indicate needle tracts. Scale bar, $250 \mu \mathrm{m}$.

of dopaminergic neurons in the SN. Alternatively, activated microglia also produce proinflammatory cytokines, including IL$1 \beta$, IL- 6 , and TNF- $\alpha$. Cytokines such as TNF- $\alpha$ may exert a direct toxicity on dopaminergic neurons.

Finally, the connection to PD depends on selective neurotoxicity against dopaminergic neurons. Regarding this, we failed to show selectivity because thrombin produced degeneration of both dopaminergic neurons and nondopaminergic neurons (GABAergic neurons) in the SN under our experimental conditions. However, despite lacking selectivity, our data allow us to carefully suggest that thrombin could contribute to death of nigral dopaminergic neurons, at least in part, through microglial activation. This microglial-mediated effect would be in addition to the direct neurotoxicity of thrombin on dopaminergic neurons. This observation appears to be important under pathological conditions, given that microglial activation is considered to play a pivotal role in the initiation of $\mathrm{PD}$, its progression, or both. Therefore, it is likely that thrombin can act as an endogenous neurotoxin and may contribute to dopaminergic neuronal cell death in PD both directly and indirectly.

\section{References}

Alessandrini A, Namura S, Moskowitz MA, Bonventre JV (1999) MEK1 protein kinase inhibition protects against damage resulting from focal cerebral ischemia. Proc Natl Acad Sci USA 96:12866-12869.

Alessi DR, Cuenda A, Cohen P, Dudley DT, Saltiel AR (1995) PD 098059 is a specific inhibitor of the activation of mitogen-activated protein kinase kinase in vitro and in vivo. J Biol Chem 270:27489-27494.

Aloisi F (2001) Immune function of microglia. Glia 36:165-179. 
Araki E, Forster C, Dubinsky JM, Ross ME, Iadecola C (2001) Cyclooxygenase-2 inhibitor ns-398 protects neuronal cultures from lipopolysaccharide-induced neurotoxicity. Stroke 32:2370-2375.

Bauer MK, Lieb K, Schulze-Osthoff K, Berger M, Gebicke-Haerter PJ, Bauer J, Fiebich BL (1997) Expression and regulation of cyclooxygenase-2 in rat microglia. Eur J Biochem 243:726-731.

Bhat NR, Zhang P, Lee JC, Hogan EL (1998) Extracellular signal-regulated kinase and p38 subgroups of mitogen-activated protein kinases regulate inducible nitric oxide synthase and tumor necrosis factor $\alpha$ gene expression in endotoxin-stimulated primary glial cultures. J Neurosci 18:1633-1641.

Boka G, Anglade P, Wallach D, Javoy-Agid F, Agid Y, Hirsch EC (1994) Immunocytochemical analysis of tumor necrosis factor and its receptors in Parkinson's disease. Neurosci Lett 172:151-154.

Brown DR (2001) Microglia and prion disease. Microsc Res Tech 54:71-80.

Castano A, Herrera AJ, Cano J, Machado A (1998) Lipopolysaccharide intranigral injection induces inflammatory reaction and damage in nigrostriatal dopaminergic system. J Neurochem 70:1584-1592.

Chao CC, Hu S, Molitor TW, Shaskan EG, Peterson PK (1992) Activated microglia mediate neuronal cell injury via a nitric oxide mechanism. J Immunol 149:2736-2741.

Cicchetti F, Brownell AL, Williams K, Chen YI, Livni E, Isacson O (2002) Neuroinflammation of the nigrostriatal pathway during progressive 6-OHDA dopamine degeneration in rats monitored by immunohistochemistry and PET imaging. Eur J Neurosci 15:991-998.

Colasanti M, Persichini T, Di Pucchio T, Gremo F, Lauro GM (1995) Human ramified microglial cells produce nitric oxide upon Escherichia coli lipopolysaccharide and tumor necrosis factor alpha stimulation. Neurosci Lett 200:144-146.

Combs CK, Johnson DE, Cannady SB, Lehman TM, Landreth GE (1999) Identification of microglial signal transduction pathways mediating a neurotoxic response to amyloidogenic fragments of $\beta$-amyloid and prion proteins. J Neurosci 19:928-939.

Debeir T, Benavides J, Vige X (1998) Involvement of protease-activated receptor- 1 in the in vitro development of mesencephalic dopaminergic neurons. Neuroscience 82:739-752.

Dehmer T, Lindenau J, Haid S, Dichgans J, Schulz JB (2000) Deficiency of inducible nitric oxide synthase protects against MPTP toxicity in vivo. J Neurochem 74:2213-2216.

Dickson DW, Lee SC, Mattiace LA, Yen SH, Brosnan C (1993) Microglia and cytokines in neurological disease, with special reference to AIDS and Alzheimer's disease. Glia 7:75-83.

Dihanich M, Kaser M, Reinhard E, Cunningham D, Monard D (1991) Prothrombin mRNA is expressed by cells of the nervous system. Neuron 6:575-581.

Ding M, St. Pierre BA, Parkinson JF, Medberry P, Wong JL, Rogers NE, Ignarro LJ, Merrill JE (1997) Inducible nitric oxide synthase and nitric oxide production in human fetal astrocytes and microglia. J Biol Chem 272:11327-11335.

Donovan FM, Pike CJ, Cotman CW, Cunningham DD (1997) Thrombin induces apoptosis in cultured neurons and astrocytes via a pathway requiring tyrosine kinase and RhoA activities. J Neurosci 17:5316-5326.

Drachman DB, Rothstein JD (2000) Inhibition of cyclooxygenase-2 protects motor neurons in an organotypic model of amyotrophic lateral sclerosis. Ann Neurol 48:792-795.

Espey MG, Chernyshev ON, Reinhard Jr JF, Namboodiri MA, Colton CA (1997) Activated human microglia produce the excitotoxin quinolinic acid. NeuroReport 8:431-434.

Fenton JW (1986) Thrombin. Ann NY Acad Sci 485:5-15.

Giasson BI, Lee VM (2001) Parkin and the molecular pathways of Parkinson's disease. Neuron 31:885-888.

Gingrich MB, Traynelis SF (2000) Serine proteases and brain damage: is there a link? Trends Neurosci 23:399-407.

Giulian D, Vaca K, Corpuz M (1993) Brain glia release factors with opposing actions on neuronal survival. J Neurosci 13:29-37.

He Y, Appel S, Le W (2001) Minocycline inhibits microglial activation and protects nigral cells after 6-hydroxydopamine injection into mouse striatum. Brain Res 909:187-193.

Hewett SJ, Uliasz TF, Vidwans AS, Hewett JA (2000) Cyclooxygenase-2 contributes to $N$-methyl-D-aspartate-mediated neuronal cell death in primary cortical cell culture. J Pharmacol Exp Ther 293:417-425.
Hirsch EC (2000) Glial cells and Parkinson's disease. J Neurol 247 [Suppl 2]:II58-II62.

Hu BR, Liu CL, Park DJ (2000) Alteration of MAP kinase pathways after transient forebrain ischemia. J Cereb Blood Flow Metab 20:1089-1095.

Hunot S, Dugas N, Faucheux B, Hartmann A, Tardieu M, Debre P, Agid Y, Dugas B, Hirsch EC (1999) FcepsilonRII/CD23 is expressed in Parkinson's disease and induces, in vitro, production of nitric oxide and tumor necrosis factor $\alpha$ in glial cells. J Neurosci 19:3440-3447.

Iadecolar C, Xu X, Zhang F, Hu J, el-Fakahany EE (1994) Prolonged inhibition of brain nitric oxide synthase by short-term systemic administration of nitro-L-arginine methyl ester. Neurochem Res 19:501-505.

Jin K, Mao XO, Zhu Y, Greenberg DA (2002) MEK and ERK protect hypoxic cortical neurons via phosphorylation of Bad. J Neurochem 80:119-125.

Kim EJ, Lee JE, Kwon KJ, Lee SH, Moon CH, Baik EJ (2001) Differential roles of cyclooxygenase isoforms after kainic acid-induced prostaglandin $\mathrm{E}(2)$ production and neurodegeneration in cortical and hippocampal cell cultures. Brain Res 908:1-9.

Kim WG, Mohney RP, Wilson B, Jeohn GH, Liu B, Hong JS (2000) Regional difference in susceptibility to lipopolysaccharide-induced neurotoxicity in the rat brain: role of microglia. J Neurosci 20:6309-6316.

Kirik D, Rosenblad C, Björklund A (1998) Characterization of behavioral and neurodegenerative changes following partial lesions of the nigrostriatal dopamine system induced by intrastriatal 6-hydroxydopamine in the rat. Exp Neurol 152:259-277.

Kirik D, Rosenblad C, Björklund A, Mandel RJ (2000) Long-term rAAVmediated gene transfer of GDNF in the rat Parkinson's model: intrastriatal but not intranigral transduction promotes functional regeneration in the lesioned nigrostriatal system. J Neurosci 20:4686-4700.

Knott C, Stern G, Wilkin GP (2000) Inflammatory regulators in Parkinson's disease: iNOS, lipocortin-1, and cyclooxygenases-1 and -2. Mol Cell Neurosci 16:724-739.

Kohutnicka M, Lewandowska E, Kurkowska-Jastrzebska I, Czlonkowski A, Czlonkowska A (1998) Microglial and astrocytic involvement in a murine model of Parkinson's disease induced by 1-methyl-4-phenyl-1, 2, 3, 6-tetrahydropyridine (MPTP). Immunopharmacology 39:167-180.

Kreutzberg GW (1996) Microglia: a sensor for pathological events in the CNS. Trends Neurosci 19:312-318.

Kulich SM, Chu CT (2001) Sustained extracellular signal-regulated kinase activation by 6-hydroxydopamine: implications for Parkinson's disease. J Neurochem 77:1058-1066.

Kunz T, Oliw EH (2001) The selective cyclooxygenase-2 inhibitor rofecoxib reduces kainate-induced cell death in the rat hippocampus. Eur J Neurosci 13:569-575.

Le W, Rowe D, Xie W, Ortiz I, He Y, Appel SH (2001) Microglial activation and dopaminergic cell injury: an in vitro model relevant to Parkinson's disease. J Neurosci 21:8447-8455.

Lee DY, Kim SU, Joe EH, Yang MS, Jin BK (2001) Thrombin induces cell death of dopaminergic neurons in mesencephalic culture: role of microglia. Soc Neurosci Abstr 27:837.9.

Li DY, Hardy P, Abran D, Martinez-Bermudez AK, Guerguerian AM, Bhattacharya M, Almazan G, Menezes R, Peri KG, Varma DR, Chemtob S (1997) Cyclooxygenase-2 in PGE2 and PGF2 alpha receptor regulation and cerebral blood flow of the newborn. Am J Physiol 273:R1283-R1290.

Liberatore GT, Jackson-Lewis V, Vukosavic S, Mandir AS, Vila M, McAuliffe WG, Dawson VL, Dawson TM, Przedborski S (1999) Inducible nitric oxide synthase stimulates dopaminergic neurodegeneration in the MPTP model of Parkinson disease. Nat Med 5:1403-1409.

McMillian MK, Vainio PJ, Tuominen RK (1997) Role of protein kinase C in microglia-induced neurotoxicity in mesencephalic cultures. J Neuropathol Exp Neurol 56:301-307.

Meda L, Cassatella MA, Szendrei GI, Otvos Jr L, Baron P, Villalba M, Ferrari D, Rossi F (1995) Activation of microglial cells by beta-amyloid protein and interferon-gamma. Nature 374:647-650.

Minghetti L, Walsh DT, Levi G, Perry VH (1999) In vivo expression of cyclooxygenase-2 in rat brain following intraparenchymal injection of bacterial endotoxin and inflammatory cytokines. J Neuropathol Exp Neurol 58:1184-1191.

Mirjany M, Ho L, Pasinetti GM (2002) Role of cyclooxygenase-2 in neuronal cell cycle activity and glutamate-mediated excitotoxicity. J Pharmacol Exp Ther 301:494-500. 
Möller T, Hanisch UK, Ransom BR (2000) Thrombin-induced activation of cultured rodent microglia. J Neurochem 75:1539-1547.

Murphy S, Simmons ML, Agullo L, Garcia A, Feinstein DL, Galea E, Reis DJ, Minc-Golomb D, Schwartz JP (1993) Synthesis of nitric oxide in CNS glial cells. Trends Neurosci 16:323-328.

Murray B, Alessandrini A, Cole AJ, Yee AG, Furshpan EJ (1998) Inhibition of the p44/42 MAPK kinase pathway protects hippocampal neurons in a cell-culture model of seizure activity. Proc Natl Acad Sci USA 95:11975-11980.

Nakajima K, Kohsaka S (2001) Microglia: activation and their significance in the central nervous system. J Biochem (Tokyo) 130:169-175.

Nishino A, Suzuki M, Ohtani H, Motohashi O, Umezawa K, Nagura H, Yoshimoto T (1993) Thrombin may contribute to the pathophysiology of central nervous system injury. J Neurotrauma 10:167-179.

Nogawa S, Zhang Fangyi, Ross ME, Iadecola C (1997) Cyclo-oxygenase-2 gene expression in neurons contributes to ischemic brain damage. J Neurosci 17:2746-2755.

Paxinos G, Watson C (1998) The rat brain in stereotaxic coordinates. San Diego: Academic.

Popovich PG, Wei P, Stokes BT (1997) Cellular inflammatory response after spinal cord injury in Sprague-Dawley and Lewis rats. J Comp Neurol 377:443-464.

Pyo HK, Jou IL, Jung SY, Hong SM, Joe EH (1998) Mitogen-activated protein kinases activated by lipopolysaccharide and $\beta$-amyloid in cultured rat microglia. NeuroReport 9:871-874.

Pyo HK, Joe EH, Jung SY, Lee SH, Jou IL (1999) Gangliosides activate cultured rat brain microglia. J Biol Chem 274:34584-34589.

Rodrigues RW, Gomide VC, Chadi G (2001) Astroglial and microglial reaction after a partial nigrostriatal degeneration induced by the striatal injection of different doses of 6-hydroxydopamine. Int J Neurosci 109:91-126.

Ryu JY, Pyo HK, Jou IR, Joe EH (2000) Thrombin induces NO release from cultured rat microglia via protein kinase $\mathrm{C}$, mitogen-activated protein kinase, and NF- $\kappa$ B. J Biol Chem 275:29955-29959.

Ryu JK, Shin WH, Kim J, Joe EH, Lee YB, Cho KG, Oh YJ, Kim SU, Jin BK (2002a) Trisialoganglioside GT1b induces in vivo degeneration of nigral dopaminergic neurons: role of microglia. Glia 38:15-23.

Ryu JY, Min KJ, Rhim TY, Kim TH, Pyo HK, Jin BK, Kim SU, Jou IL, Kim SS, Joe EH (2002b) Prothrombin kringle-2 activates cultured rat brain microglia. J Immunol 168:5805-5810.

Soifer SJ, Peters KG, O’Keefe J, Coughlin SR (1994) Disparate temporal expression of the prothrombin and thrombin receptor genes during mouse development. Am J Pathol 144:60-69.

Stence N, Waite M, Dailey ME (2001) Dynamics of microglial activation: a confocal time-lapse analysis in hippocampal slices. Glia 33:256-266.

Striggow F, Riek M, Breder J, Henrich-Noack P, Reymann KG, Reiser G (2000) The protease thrombin is an endogenous mediator of hippocampal neuroprotection against ischemia at low concentrations but causes degeneration at high concentrations. Proc Natl Acad Sci USA 97:2264-2269.

Sugino T, Nozaki K, Takagi Y, Hattori I, Hashimoto N, Moriguchi T, Nishida E (2000) Activation of mitogen-activated protein kinases after transient forebrain ischemia in gerbil hippocampus. J Neurosci 20:4506-4514.

Suo Z, Wu M, Ameenuddin S, Anderson HE, Zoloty JE, Citron BA, AndradeGordon P, Festoff BW (2002) Participation of protease-activated receptor-1 in thrombin-induced microglial activation. J Neurochem 80:655-666.

Teismann P, Ferger B (2001) Inhibition of the cyclooxygenase isoenzymes COX-1 and COX-2 provide neuroprotection in the MPTP-mouse model of Parkinson's disease. Synapse 39:167-174.

Tikka T, Fiebich BL, Goldsteins G, Keinanen R, Koistinaho J (2001) Minocycline, a tetracycline derivative, is neuroprotective against excitotoxicity by inhibiting activation and proliferation of microglia. J Neurosci 21:2580-2588.

Tomimoto H, Akiguchi I, Wakita H, Lin JX, Budka H (2000) Cyclooxygenase- 2 is induced in microglia during chronic cerebral ischemia in humans. Acta Neuropathol (Berl) 99:26-30.

Turgeon VL, Lloyd ED, Wang S, Festoff BW, Houenou LJ (1998) Thrombin perturbs neurite outgrowth and induces apoptotic cell death in enriched chick spinal motoneuron cultures through caspase activation. J Neurosci 18:6882-6891.

Vila M, Jackson-Lewis V, Guegan C, Wu DC, Teismann P, Choi DK, Tieu K, Przedborski S (2001) The role of glial cells in Parkinson's disease. Curr Opin Neurol 14:483-489.

Walker DG, Kim SU, McGeer PL (1995) Complement and cytokine gene expression in cultured microglial derived from postmortem human brains. J Neurosci Res 40:478-493.

Wang H, Xu L, Venkatachalam S, Trzaskos JM, Friedman SM, Feuerstein GZ, Wang X (2001) Differential regulation of IL-1beta and TNF-alpha RNA expression by MEK1 inhibitor after focal cerebral ischemia in mice. Biochem Biophys Res Commun 286:869-874.

Weinstein JR, Gold SJ, Cunningham DD, Gall CM (1995) Cellular localization of thrombin receptor mRNA in rat brain: expression by mesencephalic dopaminergic neurons and codistribution with prothrombin mRNA. J Neurosci 15:2906-2919.

West MJ, Slomianka L, Gundersen HJ (1991) Unbiased stereological estimation of the total number of neurons in the subdivisions of the rat hippocampus using the optical fractionator. Anat Rec 231:482-497.

Wu DC, Jackson-Lewis V, Vila M, Tieu K, Teismann P, Vadseth C, Choi DK, Ischiropoulos H, Przedborski S (2002) Blockade of microglial activation is neuroprotective in the 1-methyl-4-phenyl-1,2,3,6-tetrahydropyridine mouse model of Parkinson disease. J Neurosci 22:1763-1771.

Zhao ML, Liu JS, He D, Dickson DW, Lee SC (1998) Inducible nitric oxide synthase expression is selectively induced in astrocytes isolated from adult human brain. Brain Res 813:402-405. 